\title{
Contrast effects as a function of delay and shifts in magnitude of water reward in thirsty rats
}

\author{
KOBERT E. SPENCER and MITRI E. SHANAB \\ California State University, Fresno, California 93740
}

\begin{abstract}
In a two-shift experiment, eight independent groups of thirsty rats received the following treatments after either 0 - or 15-sec delay: LLL, LSL, SSS, SLS, with each letter denoting the magnitude of water reward received in Phases 1-3 of the experiment. In the delayed condition, significant positive (PCE) and negative (NCE) contrast effects were obtained following the first shift, but only a weak PCE in the second shift. In the immediate reward condition, neither a PCE nor a NCE was obtained in either shift. The present findings are discussed in terms of several theories of contrast. The need for considerably more empirical investigations of shifts in the parameters of water reward was indicated.
\end{abstract}

Numerous studies have been reported dealing with successive contrast effects produced by shifts in the conditions of instrumental learning situations (Cox, 1975; Dunham, 1968). Successive contrast effects are investigated in experiments in which subjects initially receive consistent training with one level of reward and are subsequently shifted to a different reinforcement condition. A positive contrast effect (PCE) occurs when subjects shifted from a small to a larger reward perform at a significantly higher level than control subjects receiving the large reward all the time. A negative contrast effect (NCE) occurs when subjects shifted from a large to a smaller reward perform at a significantly lower level than control subjects receiving the small reward all the time.

The rewards used in most contrast studies have consisted primarily of food pellets, and less frequently, of sucrose solutions and water. The results of investigations using delay of food reward have not been consistent with respect to either PCE or NCE. Such studies have found a NCE but no PCE (Shanab \& Biller, 1972), found no NCE (Mackintosh \& Lord, 1973), found neither a PCE nor a NCE (Shanab, Rouse, \& Cavallaro, 1973), or found no PCE (McCain, Lobb, Almand, \& Leck, 1976). The results of shifts in the magnitude of food reward have been less ambiguous. While successive NCE is consistently obtained, a comparable PCE is very difficult to find (Cox, 1975; Dunham, 1968). With the introduction of a delay interval to control for possible ceiling effects (cf. Bower, 1961), however, a reliable PCE has been obtained (Mellgren, 1972; Shanab, Sanders, \& Premack, 1969). Repeated-shifts procedures, in which subjects are shifted back to a reward level they have previously experienced, have also produced PCE and NCE (Benefield, Oscos, \& Ehrenfreund, 1974; McCain, Lobb, Almand, \& Leck, 1976; McCain, Lobb, \& Newberry, 1976). Multiple shifts,

This paper is based in part on the first author's master's thesis. Reprint requests should be sent to Mitri E. Shanab, Department of Psychology, California State University, Fresno, California 93740. in which two or more independent variables are simultaneously shifted, have also resulted in PCE (Shanab \& Biller, 1972; Shanab \& Cavallaro, 1975).

Until recently, no NCE could be obtained based on downshifts of magnitude or concentration of sucrose reward (Barnes \& Tombaugh, 1973; Flaherty, Riley, \& Spear, 1973; Ison \& Rosen, 1968). With a repeated-shifts procedure, a NCE was found with shifts in magnitude of sucrose reward (Shanab, France, \& Young, 1976), as well as with shifts in delay of sucrose reward (Shanab, Domino, \& Melrose, 1977), although no PCE was found in the latter study.

Very few studies have used water as reward. Shifting delay of water reward, Sgro and Weinstock (1963) reported a PCE based on a restricted sample. In a similar design, Ferrell and Shanab (1975) did not obtain a PCE or a NCE. Shanab and Spencer (1978) conducted perhaps the first reported investigation of contrast effects as a function of shifts in magnitude of water reinforcement. In their study, subjects were given 48 acquisition trials in a runway with a reward of either 2- or 20-sec access to water after a delay interval of $20 \mathrm{sec}$. In the shift phase, the experimental subjects were given the opposite reward. A significant PCE was obtained for the upshifted group over the entire phase. The depressive effect of the extended delay interval, however, seemed to result in a floor effect that precluded the occurrence of a sustained NCE. A significant NCE was found on Trial 2 in the run section of the runway over the last six blocks of the phase.

The present investigation attempted to isolate the conditions that facilitate the emergence of contrast effects in water-deprived subjects. Three variables in particular seemed to be important. First, the introduction of a delay interval before the receipt of reward was used to control for any ceiling effects that might preclude the emergence of a PCE. A 15-sec interval was used, rather than the 20sec interval of the earlier study (Shanab \& Spencer, 1978), so as not to depress running speed to a level that would preclude the development of a NCE. Second, massed 
rather than the more common spaced learning trials were used, since Capaldi (1972) has shown that a larger NCE can be obtained using massed rather than spaced trials. The third variable incorporated into the design was the repeated-shifts procedure. Repeated shifts have been successfully used to obtain a PCE in studies using food reward (Benefield et al., 1974) and a PCE and NCE using sucrose reward (Shanab et al., 1976).

\section{METHOD}

\section{Design}

The experiment consisted of three Phases. In Phase 1, 20 subjects were assigned to each of four reward conditions: access to water for $2 \mathrm{sec}(\mathrm{S})$ or $20 \mathrm{sec}(\mathrm{L})$ after a delay of 0 or $15 \mathrm{sec}$. In Phase 2, each main group was divided in half, resulting in eight groups with 10 subjects/group, according to a 2 by 2 by 2 factorial design. One subgroup continued to receive the same reward magnitude as before; the second subgroup was shifted to the other reward magnitude. In Phase 3, subjects were shifted back to their respective conditions of Phase 1 . Thus, the four groups run for both the delayed and nondelayed conditions were: LLL, LSL, SSS, SLS, with the letters representing the reward magnitude received in each of the three phases, respectively.

\section{Subjects}

The subjects were 80 naive male albino rats of the SpragueDawley strain, about 90 days old at the beginning of the study.

\section{Apparatus}

The runway used was the same $1.5-\mathrm{m}$ runway described by Shanab and Spencer (1978). A series of photocells measured running speed over the start $(15 \mathrm{~cm})$, run $(71.5 \mathrm{~cm})$, and goal $(30.5 \mathrm{~cm})$ sections .

\section{Procedure}

The subjects were housed in individual cages with free access to food and water and were handled daily for 2 min for 18 days. They were then placed on a $23.75-\mathrm{h}$ water-deprivation schedule. At least $30 \mathrm{~min}$ after handling each day, subjects were given water access for $15 \mathrm{~min}$. After 13 days on the deprivation schedule, they were given $90-\mathrm{sec}$ unrewarded exploration trials in the runway for 7 days. The subjects were then randomly assigned to the four main groups, and Phase 1 (15 days) was started. On the first 2 days, each subject received 1 trial/day, and 2 trials/day thereafter. Trials were massed with an intertrial interval of approximately $10 \mathrm{sec}$. Throughout the study, the reinforcer used consisted of either a 2- or a 20 -sec access to the drinking tube after a delay of either 0 or $15 \mathrm{sec}$. The delay interval began when the subject broke the last photobeam located within the goalbox. Subjects received their 15-min daily ration of water at least $30 \mathrm{~min}$ after Trial 2.

In Phase 2, subjects were matched on the basis of asymptotic performance levels in Phase 1 and were divided into subgroups, with the reward changed to the opposite magnitude for half the subjects in each of the four main groups. Phase 2 continued at 2 trials/day for 14 days. In Phase 3 (14 days) subjects were returned to their respective conditions of Phase 1 . In all phases, subjects had free access to food.

\section{RESULTS}

All analyses are based on speed measures (meters/ second). An ANOVA with repeated measures over the last four blocks of Phase 1 yielded nonsignificant results for both blocks and the interaction of Blocks by Delay $[\mathrm{Fs}(3,288)=2.11$ and 1.53 , respectively, ps $>.05]$, suggesting that the groups had stabilized before the first shift. A significant delay effect was obtained $[F(1,76)=$ $21.37, \mathrm{p}<.01]$, indicating faster running speeds for the immediately rewarded groups in comparison to the delayed groups. The main effect of blocks and the Delay by Blocks, Magnitude by Blocks, and Delay by Magnitude by Blocks interactions were all nonsignificant $(\mathrm{Fs}<1)$.

As Figure 1 shows, in the delay condition the upshifted group (SL) ran faster in Phase 2 than its control group (LL), displaying a PCE. At Block 5, the speed of the downshifted group (LS) was depressed below the level of its control group (SS), reflecting a NCE. Figure 1 also shows that there were no large changes in the running speeds of either shifted group in the nondelay condition. A three-way ANOVA test of the total speed measure with delay, Phase 1 , and Phase 2 conditions as the between-subjects factors was performed over all blocks. The results yielded significant main effects for delay $[F(1,72)=45.75, p<.01]$ and for Phase 1 and Phase 2 conditions $[\mathrm{Fs}(1,72)=8.16$ and 4.79 , ps $<.01$ and $<.05$, respectively]. None of the interactions was significant. A test of simple effects revealed a significant PCE based on a comparison between Groups SL and LL in the delay condition $[F(1,72)=9.89, p<.01]$; no NCE was obtained when Groups LS and SS were compared $[F(1,72)=1.50, p>.05]$. When similar comparisons were made for the nondelay condition, neither a significant PCE nor a significant NCE was obtained (Fs $<1$ ). To check the reliability of the graphical NCE, a threeway ANOVA was performed over Blocks 5-14, yielding significant main effects for the delay and Phase 1 conditions $[F s(1,72)=39.39$ and 9.63 , ps $<.01]$ and for Phase $2[F(1,72)=5.82, p<.05]$. None of the interactions was significant. A simple effects test for the delayed groups revealed a significant PCE $[\mathrm{F}(1,72)=9.39, \mathrm{p}<$ $.01]$, as well as a significant $\operatorname{NCE}[F(1,72)=4.05, p<$ $.05]$. The differences between the nondelayed groups were again nonsignificant (Fs $<1$ ). Separate analyses of the start, run, and goal speeds yielded essentially the same results as the total speed analysis; namely, significant PCE and NCE were found under delayed but not under immediate reinforcement conditions.

ANOVAs were performed on the mean start, run, and goal speeds for Trials 1 and 2 separately. On Trial 1, a PCE was found in the start measure in the delay condition

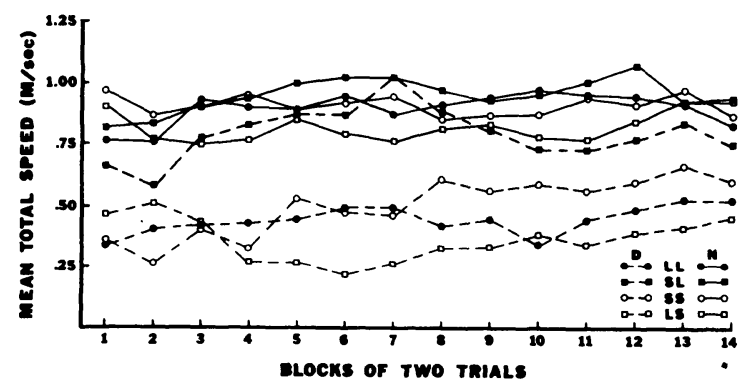

Figure 1. Mean total speed as a function of shifts in magnitude of water reward under delayed (D) and nondelayed (N) conditions. 
$[F(1,72)=4.29, p<.05] ;$ none of the other comparisons yielded a significant PCE or NCE. On Trial 2, however, a PCE was obtained under delayed conditions in the start, run, and goal speeds $[F s(1,72)=12.79,11.73$, and 8.20 , respectively, all ps $<.01$ ] . A significant NCE was found in the delay condition on Trial 2 of the run speed only $[F(1,72)=8.08, p<.01]$. None of the nondelay comparisons was significant (all Fs $<1$ ).

In Phase 3, no large differences in performances appeared for any of the shifted groups in comparison to controls under either delay condition. In the delay condition, a slight graphical PCE emerged over Blocks 2-11, as did a graphical NCE over Blocks 5-8. In the nondelay condition, a graphical PCE appeared over all blocks. Analysis of the total speed measure over Blocks 2-11 yielded a significant main effect for delay $[F(1,72)=$ $28.11, \mathrm{p}<.01]$. Neither the Phase 3 main effect nor the Delay by Phase 3 interaction effect was significant $($ Fs $<1)$. The results of simple effects for PCE and NCE were not significant. Separate analyses of the start, run, and goal speeds yielded highly similar results.

Upon closer inspection of the data, a graphical PCE was detected in the total speed of Trial 2 under delayed conditions. The upshifted group ran faster than its control over Blocks $2-11$, as revealed by the results of a simple effects test $[F(1,72)=6.14, p<.025]$. Similar results were obtained in the Trial 2 goal speeds over Blocks 2-13 $[F(1,72)=3.98, p<.05]$.

\section{DISCUSSION}

The most important finding of the present investigation was the occurrence of both a PCE and a NCE in the delay condition during the first shift. These results replicate the earlier results of Shanab and Spencer (1978), indicating that the use of a moderate delay interval facilitated the emergence of PCE as well as NCE. The present findings also show that massed trials produced stronger contrast than spaced trials, since both the PCE and NCE were stronger on Trial 2 than on Trial 1. In the nondelay condition, the lack of a PCE was predicted, but the absence of a NCE was not. The downshifted group did run slower than its control group, but the difference was not statistically significant.

The contrast effects obtained in the delay condition of the present study are in agreement with other studies using superimposed delay with shifts in magnitude of food reward (Mellgren, 1972; Shanab \& Cavallaro, 1975; Shanab et al., 1969). The failure to obtain contrast effects in the nondelay condition is consistent with sucrose studies in which initial shifts in magnitude of reward did not result in a PCE (Shanab et al., 1976) or a NCE (Flaherty et al., 1973; Shanab et al., 1976). Although a NCE is usually readily obtained in food studies under nondelay conditions (Dunham, 1968), some studies have reported negative results for NCE (Weinstock, 1971), as well as for PCE (McCain, Lobb, \& Newberry, 1976).

The only significant contrast effect to emerge in Phase 3 was a PCE in the delay condition on Trial 2 of the total and goal speeds. This rather weak effect provides only limited support for the prediction that repeated shifts would facilitate the emergence of contrast effects. The failure to obtain a NCE in the delay condition and the absence of a PCE or NCE in the nondelay condition are obviously inconsistent with this prediction. The present results receive support from other studies in which a second shift in magnitude of food reward produced neither a significant PCE nor a significant NCE (McCain, Lobb, \& Newberry, 1976; Weinstock, 1971). These findings, however, are to be contrasted with those of other studies that obtained contrast effects during a second shift with both food reward (Benefield et al., 1974) and sucrose reward (Shanab et al., 1976).

The present investigation and the Shanab and Spencer (1978) study are apparently the only reported studies that have obtained significant contrast effects following shifts in the magnitude of water reward with superimposed delay. Thus, the results cannot be directly compared to other studies, which makes it more difficult to interpret the results. The PCE and NCE obtained in the delay condition in the first shift are consistent with the relative views of Crespi (1944) and Helson (1964), which interpret these effects as due to either an over- or underestimation of the reward magnitude received in comparison with the preshift magnitude. The results also support the reinforcement-level view (Capaldi, 1974, Note 1), which proposes that contrast effects are a function of the discrepancy between expected and obtained reward. The predicted lack of a PCE in the nondelay condition can be attributed to the ceiling effects inherent in the running response (cf. Bower, 1961). It is also consistent with reinforcement-level theory that predicts that when a PCE does occur it will be larger and presumably more reliable under delayed than under immediate reward conditions (Capaldi, Note 1). The lack of a NCE in the nondelay condition, however, is puzzling. This failure could be attributed to properties of the reinforcer used. Some studies have shown that water reinforcement does not always lead to the same effects as food reinforcement. For example, Snyder and Hulse (1961) found that neither volume nor number of licks of water reward had any effect on running speed during acquisition or extinction. Logan and Spanier (1970) found that under short delay (1 sec), hungry rats ran faster than thirsty rats, while the opposite was true under long delay $(30 \mathrm{sec})$. Ferrell and Shanab (1975) found neither a significant PCE nor a significant NCE following shifts in delay of water reward.

To explain the lack of NCE in the nondelay condition, one could argue that downshifts in water reward produce only minimal frustration. An experiment by Levy and Seward (1969) lends strong support to this contention. Thirsty and hungry rats were tested for the "frustration effect" in a double runway in which the sequence of rewards in the first and second goalboxes was food followed by food, food-water, water-water, and waterfood. The test consisted of measuring the increase in speed in the second alley following omission of the reward in the first goalbox. While a significant frustration effect was found in the food-food and food-water groups, no such effect was found in the waterwater or water-food groups, suggesting that a downshift to zero magnitude of water reward does not produce a measurable frustration effect. This would explain the absence, in this study, of a NCE under immediate reward conditions. Under delayed conditions, however, a NCE would be expected as a result of the frustration produced by the delay interval itself in addition to whatever frustration is produced by the downshift. The postulation of minimal frustration would be consistent with several of Capaldi's views (1972, 1974, Note 1) and Amsel's (1967) theory, which share the assumption that NCE is a function of the frustration developed during the downshift.

It is clear that the present results pose difficulties for the major theories of contrast, partly because of the inadequacy of the theories, but mainly because of the paucity of empirical studies based on shifts in the parameters of water reinforcement.

\section{REFERENCE NOTE}

1. Capaldi, E. Reinforcement level: An expectancy-associative approach to relative reinforcement and nonreinforcement effects. Paper presented at the Arlington Symposium, Arlington, Vermont, 1974. 


\section{REFERENCES}

AMSEL, A. Partial reinforcement effects on vigor and persistence. In K. Spence \& J. Spence (Eds.), The psychology of learning and motivation (Vol. 1). New York: Academic Press, 1967.

Barnes, W., \& Tombaugh, T. Another failure to obtain negative contrast following reductions in sucrose reward. Psychological Reports, 1973, 33, 801-802.

Benefield, R., Oscos, A., \& Ehrenfreund, D. Role of frustration in successive positive contrast. Journal of Comparative and Physiological Psychology, 1974, 86, 648-651.

BowER, G. A contrast effect in differential conditioning. Journal of Experimental Psychology, 1961, 62, 196-199.

CAPAlDI, E. Successive negative contrast effect: Intertrial interval, type of shift, and four sources of generalization decrement. Journal of Experimental Psychology, 1972, 96, 433-438.

CAPALDI, E. Partial reward either following or preceding consistent reward: A case of reinforcement level. Journal of Experimental Psychology, 1974, 102, 954-962.

Cox, W. A review of recent incentive contrast studies involving discrete-trial procedures. Psychological Record, 1975, 25, 373-393.

CREspi, L. Amount of reinforcement and level of performance. Psychological Review, 1944, 51, 341-357.

DunhaM, P. Contrasted conditions of reinforcement: A selective critique. Psychological Bulletin, 1968, 69, 295-315.

Ferrell, H., \& Shanab, M. Contrast effects as a function of shifts in delay of water reward. Bulletin of the Psychonomic Society, 1975, 5, 417-420.

Flaherty, C., Riley, E., \& Spear, N. Effects of sucrose concentration and goal units on running behavior in the rat. Learning and Motivation, 1973, 4, 163-175.

Helson, H. Adaptation-level theory. New York: Harper \& Row, 1964.

Ison, J., \& Rosen, A. Extinction and reacquisition performance as a function of sucrose-solution rewards and number of acquisition trials. Psychological Reports, 1968, 22, 375-379.

LEVY, N., \& SEWARD, J. Frustration and homogeneity of rewards in the double runway. Journal of Experimental Psychology, 1969, 81, 460-463.

Logan, F., \& SPANIER, D. Relative effects of delay of food and water reward. Journal of Comparative and Physiological Psychology, 1970, 72, 102-104.

Mackintosh, N., \& LORD, J. Simultaneous and successive contrast with delay of reward. Animal Learning \& Behavior, 1973, 1, 283-286.

McCain, G., Lobb, M., Almand, W., \& Leck, D. Delay of reinforcement: Extended training and multiple shifts. Bulletin of the Psychonomic Society, 1976, 7, 539-541.

McCAIN, G., Lobb, M., \& NewberRy, J. Extended training and multiple shifts: Percentage of reward. Bulletin of the Psychonomic Society, 1976, 8, 191-132.

MELlGREN, R. Positive and negative contrast effects using delayed reinforcement. Learning and Motivation, 1972, 3, 185-193.

Sgro, J., \& Weinstock, S. Effects of delay on subsequent running under immediate reinforcement. Journal of Experimental Psychology, 1963, 66, 260-263.

Shan AB, M., \& Biller, J. Positive contrast in the runway obtained following a shift in both delay and magnitude of reward. Learning and Motivation, 1972, 3, 179-184.

Shanab, M., \& Cavallaro, G. Positive contrast obtained in rats following a shift in schedule, delay, and magnitude of reward. Bulletin of the Psychonomic Society, 1975, 5, 109-112.

Shanab, M., Domino, J., \& Melrose, S. The effects of shifts in delay of liquid sucrose reward in thirsty rats. Bulletin of the Psychonomic Society, 1977, 10, 287-290.

Shanab, M., France, J., \& Young, T. Positive and negative contrast effects obtained following shifts in liquid sucrose reward in thirsty rats. Animal Learning \& Behavior, 1976, 4, 9-12.

Shanab, M., Rouse, L., \& Cavallaro, G. Effects of shifts in delay of reward in rats as a function of reward magnitude. Journal of General Psychology, 1973, 89, 59-66.

Shanab, M., Sanders, R., \& Premack, D. Positive contrast in the runway obtained with delay of reward. Science, 1969 , 164, 724-725.

Shanab, M., \& Spencer, R. Positive and negative contrast effects obtained following shifts in delayed water reward. Bulletin of the Psychonomic Society, 1978, 12, 199-202.

SNYDER, H., \& HULSE, S. Effect of volume of reinforcement and number of consummatory responses on licking and running behavior. Journal of Experimental Psychology, 1961, 61, 474-479.

WEINSTOCK, L. Preacquisition exploration of the runway in the determination of contrast effects in the rat. Journal of Comparative and Physiological Psychology, 1971, 75, 107-115.

(Received for publication November 20, 1978.) 